\title{
FABRICATION AND EXPERIMENT OF AN ELECTRICAL GENERATOR FOR SEA WAVE ENERGY
}

\author{
Nguyen Van Hai ${ }^{*}$, Nguyen Dong Anh, Nguyen Nhu Hieu \\ Institute of Mechanics, Vietnam Academy of Science and Technology \\ 264 Doi Can Str., Ba Dinh Dist., Ha Noi \\ "Email: nguyenvanhai1977@gmail.com
}

Received: 30 December 2016; Accepted for publication 5 September 2017

\begin{abstract}
This paper presents some results of fabrication and experiment of an electrical generator for sea wave energy. The electrical generator device is fixed on the bottom of the sea and works in the vertical direction of sea waves. The experiment results show that, for the received voltage and current, the power of the electrical generator is up to $300 \mathrm{~W}$ and operates stably at about $200 \mathrm{~W}$ during experiment at sea. The output voltage is at $220 \mathrm{VAC}$ frequency 50 $\mathrm{Hz}$ and is a pure sine wave.
\end{abstract}

Keywords: renewable energy, sea wave energy, electrical generator.

\section{INTRODUCTION}

According to calculations by scientists, the received energy from fossil fuels will become gradually exhausted, and now therefore looking for new energy sources is requisite. For Vietnam, the 2020 target is to become a country in which marine economics will constitute over $50 \%$ of GDP. Therefore, the energy demand supplying for general economics and particular marine economics is very important. The research and fabrication of electrical generators for sea wave energy are necessary. Moreover, the electrical energy received from sea wave energy conversion is friendly to environment, almost endless and is a clean energy source. The sea wave energy is an important energy source of the world as well as Vietnam in the future.

In this paper, we present some results of designing, fabrication and experiment of the electrical generator at the sea with the output voltage being $220 \mathrm{VAC}$ frequency $50 \mathrm{~Hz}$ and being pure sine wave. The electrical generator can be used for signal buoys of seaway and can supply the electrical power for lighthouses.

\section{ANALYSIS OF THE DEVICE MODEL}

In the world, the research and fabrication of the electrical generators for sea wave energy source have been considered for a long time. The received electrical energy source for wave energy conversion has met some demands of society. Up to now, the electrical generators from sea wave energy have been investigated and fabricated in many countries, for example, 
Australia, Britain, China, Denmark, Ireland, Italy, Japan, Portugal, Spain, Sweden, South Korea, the United States [1]. The devices models are categorized into two major kinds, the device fixed on the bottom of the sea and the floating device on the sea [1 - 14].

The electrical generator devices fixed on the bottom of the sea usually use the linear generators. In Ref. [2], the device is connected with a buoy on the sea surface by a rope moving in vertical direction under the action of sea waves. The power of this device is about $10 \mathrm{~kW}$. In Ref. [3], Stelzer and Joshi have evaluated buoy heave responses for a wave energy generator based on a linear model. The authors calculated the buoy motion to determine the coupled hydrodynamic and electromagnetic coefficients of the electrical power generator for both regular and irregular waves. In a monograph by Eriksson [5], the author has developed a model of a wave energy converter using linear potential wave theory in order to describe the wave-buoy interaction and effects of modeling parameters on device system dynamics. A significant topic on the optimization of wave energy converter is presented by Cargo et al. [6]. That work is devoted to the investigation of technology of generic point-absorber converter for irregular waves using a hydraulic power take-off unit of wave energy converter. Another detailed research on the optimization of sea wave energy harvesting electromagnetic device is carried out by Marco Trapanese [7]. He studied optimal characteristics of a permanent magnet linear generator using a mathematical model of system including the stochastic features of the model. An approach to the conversion of the power generated by a sea wave power generator integrated in an offshore wind power farm has been proposed by Franzitta et al. [8]. The authors compared two possible ways to connect the generator to the network and to the offshore wind power farm based on a conversion subsystem and a DC-AC converter, respectively. In Ref. [9] by Engstrom et al., a wave energy converter with enhanced amplitude responses is studied based on a theoretical model for passive systems having optimum amplitude response at frequencies coinciding with Swedish west coast conditions. A comprehensive review on the linear generator and related modern devices can be seen in Ref. [10]. In this review Ekstrom et al. have categorized, described and compared different generators for wave energy converters based on technologies of electrical damping circuits and techniques of power output optimization.

The electrical generator devices floating on the sea surface consist of the two main types, a vertical-floating type and a horizontal-floating type. The vertical floating electrical generator device consists of an oscillating upper part (the floater) and a bottom-fixed lower part (the basement) with the fixed installed linear generator. The floater is pushed down under a wave crest and moves up under a wave trough. This motion makes the generator work to generate the power about $10 \div 80 \mathrm{~kW}[1,4,11-14]$. The horizontal floating device can be illustrated here, such as a pelamis device that it looks like a snack. The structure of pelamis composes of four cylindrical sections linked by hinged joints, and aligned with the wave direction. The waveinduced motion of these joints is resisted by hydraulic rams, which pump high-pressure oil through hydraulic motors driving three industrial electrical generators. The power of this device is about $750 \mathrm{~kW}[1,4,14]$.

In Vietnam, several research institutions have fabricated electrical generators for sea wave energy. At Hanoi University of Science and Technology, and the National Research Institute of Mechanical Engineering, the researchers have calculated device models with industrial generating motors installed on fixed frame structures, and the buoy of device floating on the sea surface. The hydraulic diver system will transmit the obtained sea wave energy from the buoy to the generating motor [15]. At Vietnam National University, the researchers have 
fabricated linear electrical generators that operate and float on the sea surface in vertical direction. The initial experimental output voltage on load is received about $1 \mathrm{~V}[16,17]$.

To minimize the influence of sea storms on the device operating at sea, we build an electrical generator model with the generator part fixed on the bottom of the sea with the small and medium power (see Fig. 1). The device works in the vertical direction, and the buoy of device floats on the sea surface. When sea waves act on the buoy, it will transfer the sea wave energy to the generating motor through a rope in the vertical direction and a rotational mechanical structure system [18]. In this study, we use a type of industrial generating motor and a voltage stabilizer with high performance (see Fig. 4 a,b), and fabricate a block DC-AC inverter to generate the output voltage at $220 \mathrm{VAC}$ frequency $50 \mathrm{~Hz}$ and pure sine wave. The electrical generator model poses an advantage in that it may be not affected by waves and sea storms impacts because the generator part is fixed on the seabed.

\section{MODELLING OF THE ELECTRICAL GENERATOR}

The electrical generator device is fabricated for converting sea wave energy into electrical energy. This requires a system that can convert the vertical slow motion of buoy to a high speed rotating motion at the input of generating motor. The main structures of device include circular cylinder-shaped buoy, rope, piston-rack, gearbox, generating motor, block of 12 VDC voltage stabilizer, DC-AC inverter and protection system with the generating voltage being $220 \mathrm{VAC}$ frequency $50 \mathrm{~Hz}$ and pure sine wave, as shown in Fig. 1.

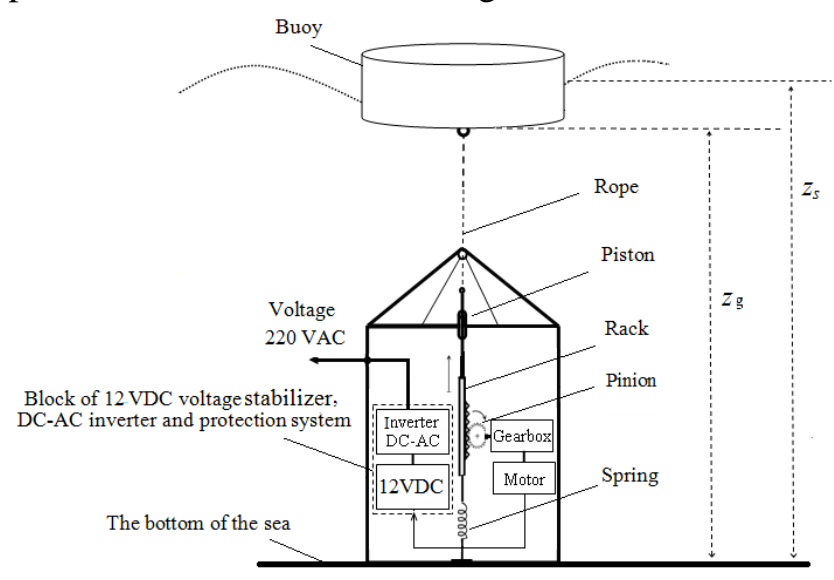

Figure 1. Schematic illustration of an electrical generator for sea wave energy.

The governing equation of buoy associated with piston-rack, as shown in Fig. 1, can be written as follows [7, 8]:

$$
m \frac{d^{2} z_{g}}{d t^{2}}=\rho g S_{b}\left(z_{S}-z_{g}\right)-m g-\gamma \frac{d z_{g}}{d t}-k_{S}\left(z_{g}-z_{0}\right),
$$

where $m$ is total mass of the buoy and the piston-rack, $z_{g}=z_{g}(t)$ is the vertical coordinate describing the position of the buoy at time $\mathrm{t}$; $\rho$ is the water density, $g$ is the acceleration gravity, $S_{b}$ is the bottom area of the buoy, $z_{s}$ is the vertical coordinate describing the sea level from the 
seabed; the damping constant $\gamma$ is the sum of the fluid damping $\left(\gamma_{f}\right)$ and the electrical generator damping $\left(\gamma_{e g}\right)$, i.e. $\gamma=\gamma_{f}+\gamma_{e g} ; k_{s}$ is the spring constant, $z_{0}$ is the rest position.

The Eq. (1) will be solved to find optimal parameters in order use for designing and fabrication of the device. For simplicity, the sea wave can be modeled as a harmonic fluctuation about the rest position $z_{0}$

$$
z_{S}=H \sin (\omega t)+z_{0},
$$

where $H$ and $\omega$ are the wave amplitude and frequency, respectively. Substituting Eq. (2) into Eq. (1) and then solving for $z_{g}$, we obtain

$$
z_{g}=\frac{k_{s} z_{0}-m g+\rho g S_{b} z_{0}}{k_{s}+\rho g S_{b}}+\chi \sin \left(\omega t+\varphi_{0}\right)
$$

where the amplitude $\chi$ and phase constant $\varphi_{0}$ are determined as follows

$$
\begin{gathered}
\chi=\frac{\rho g S_{b} H}{\sqrt{\left(k_{s}+\rho g S_{b}-m \omega^{2}\right)^{2}+\gamma^{2} \omega^{2}}}, \\
\tan \varphi_{0}=-\frac{\gamma \omega}{k_{s}+\rho g S_{b}-m \omega^{2}} .
\end{gathered}
$$
[2]:

The average of power $P_{g m}$ extracted from the wave by the converter in a period is given by

$$
P_{g m}=\frac{1}{T} \int_{0}^{T} \gamma_{e g} \dot{z}_{g}^{2} d t
$$

in which the damping coefficient of fluid, $\gamma_{f}$, is assumed to be very small in comparison with the electrical generator damping $\gamma_{e g}$ [19], and can be neglected. The output electrical power $P$ received from an electrical generator is determined as follows:

$$
P=\eta P_{g m},
$$

where $\eta$ is a power performance value of the electrical generator. It is seen that the amplitude $\chi$ can be considered as a function of the frequency $\omega$, i.e. $\chi=\chi(\omega)$, therefore the electrical power $P$ is also a function of the frequency $\omega$.

The power simulation results for the present device are shown in Fig. 2 with parameters $\rho=$ $1020 \mathrm{~kg} / \mathrm{m}^{3}, g=9.81 \mathrm{~m} / \mathrm{s}^{2}, m=30 \mathrm{~kg}, S_{b}=0.5024 \mathrm{~m}^{2}, k_{\mathrm{s}}=2100 \mathrm{~N} / \mathrm{m}, z_{0}=5.5 \mathrm{~m}$, and $\gamma_{e g}=3400$ $\mathrm{Ns} / \mathrm{m}$. Fig. 2 portrays the power curves depending on the frequency of sea wave with various values of the wave amplitude, $H_{1}=0.4 \mathrm{~m}, H_{2}=0.5 \mathrm{~m}, H_{3}=0.6 \mathrm{~m}$, and $H_{4}=0.7 \mathrm{~m}$.

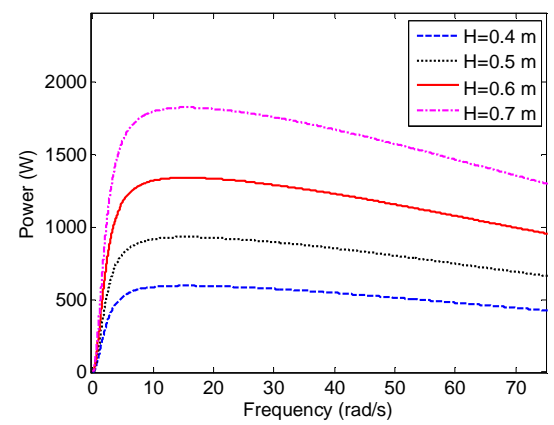

Figure 2. Power of the output electrical generator versus frequency. 
For the linear model of the buoy motion (Eq.1), it is seen that the obtained power will be extended in all range of frequency if the wave amplitude increases. In the sea experimental test of device, the sea wave amplitude value is estimated at about $0.4 \mathrm{~m} \div 0.5 \mathrm{~m}$; the sea wave frequency arises primarily at $1.472 \mathrm{rad} / \mathrm{s}$ (see Fig. 6). The range of received power belongs to interval $199 \mathrm{~W} \div 311 \mathrm{~W}$. At various frequencies, the corresponding power values of the electrical generator are received as shown in Fig. 2.

\section{FABRICATION OF THE ELECTRICAL GENERATOR}

\subsection{Structural design}

The structure of device is designed in two parts: the buoy of device floating on the surface of sea which is designed in the circular cylinder shape and the generator part fixed on the bottom of the sea. Mechanical structures and a generating motor are installed inside the casing of circular cylinder-shaped device, as shown in Fig. 3. The main parameters of the electrical generator are presented in Table 1. The buoy of device is connected to a piston shaft of the electrical generator by a rope.

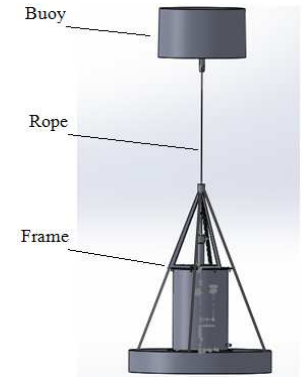

a. The electrical generator

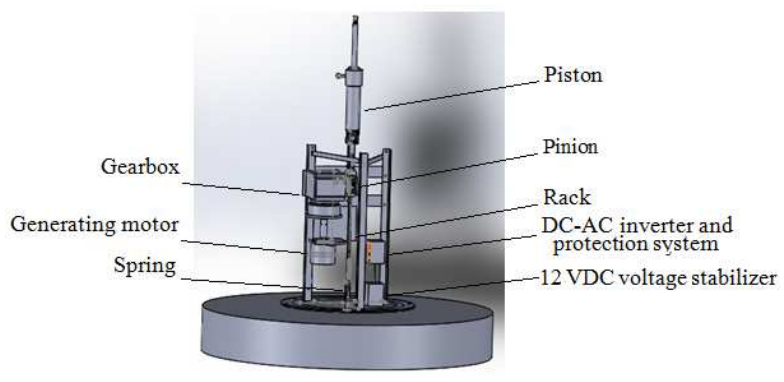

b. Inner of the electrical generator

Figure 3. Main structural components of the electrical generator.

The buoy and the casing of device are fabricated from stainless steel sheets with $3 \mathrm{~mm}$ in depth. The piston-rack, pinion and inner mechanical structures are also fabricated from stainless steels.

Table 1. The main parameters of the electrical generator.

\begin{tabular}{|l|c|l|c|}
\hline \multicolumn{1}{|c|}{ Parameters } & Value & \multicolumn{1}{c|}{ Parameters } & Value \\
\hline Buoy radius $(\mathrm{mm})$ & 400 & Piston length $(\mathrm{mm})$ & 400 \\
\hline Buoy height $(\mathrm{mm})$ & 420 & Rack length $(\mathrm{mm})$ & 450 \\
\hline Device casing height $(\mathrm{mm})$ & 750 & Pinion diameter $(\mathrm{mm})$ & 60 \\
\hline Device casing diameter $(\mathrm{mm})$ & 500 & Gearbox ratio & $1: 30$ \\
\hline
\end{tabular}

\subsection{Generating motor and voltage stabilization}

In this model, we use a generating motor that it is the AC three-phase type permanent magnet motor, and the 12 VDC voltage stabilizer with the input voltage received from AC threephase voltage of the generating motor. These equipments were imported from American WindBlue Power Company (see Fig. 4) [20]. 


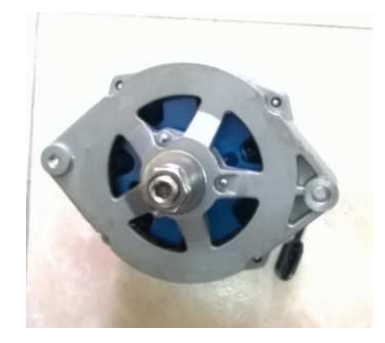

a. The generating motor

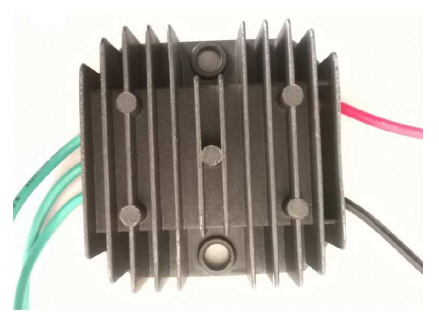

b. The $12 \mathrm{VDC}$ voltage stabilizer

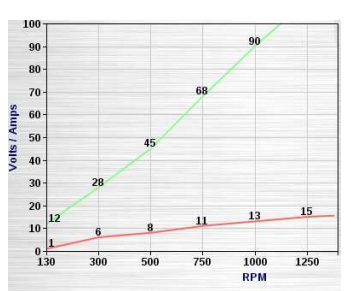

c. The voltage and current characteristics versus rotation speed of the generating motor

Figure 4. The generating motor and 12 VDC voltage stabilizer.

The power of generating motor can grow to $1500 \mathrm{~W}$ (see Fig. 4c). The output voltage from the 12 VDC voltage stabilizer is connected to the input of DC-AC inverter to generate the voltage at $220 \mathrm{VAC}$ frequency $50 \mathrm{~Hz}$ and in a pure sine wave form.

\subsection{DC-AC inverter and protection system}

The main structures of DC-AC inverter and protection system (as shown in Fig. 5) include DC-DC converter circuit block, oscillating circuit block, DC-AC converter and protection circuit block, and filter circuit block [21,22]. The main function blocks in the scheme are described as follows:

- The DC-DC converter circuit block: the function of this circuit block is to convert a low voltage $12 \mathrm{VDC}$ to high voltage $330 \mathrm{VDC}$ with the maximum input current up to $180 \mathrm{~A}$. In this circuit block, we use 5 ferrite transformers of $400 \mathrm{~W}$-type power, transistor couples of type IRF 1404 (such as Q1\&Q2, Q3\&Q4, Q5\&Q6, Q7\&Q8, Q9\&Q10), and an oscillating circuit generating an alternating current at frequency $33 \mathrm{kHz}$ using the IC TL494C. The input and output values of ferrite transformer are calculated and designed based on input 12 VDC voltage and output 330 VDC voltage. After calculation, the input and output parameters of ferrite transformer are given in Table 2. Three geometric parameters of the size $15 \mathrm{~mm} \times 15 \mathrm{~mm} \times 50 \mathrm{~mm}$ are obtained (i.e. width $\times$ length $\times$ high, respectively).

Table 2. Input and output parameters of the ferrite transformer.

\begin{tabular}{|l|c|l|c|}
\hline \multicolumn{1}{|c|}{ Parameters } & Value & \multicolumn{1}{|c|}{ Parameters } & Value \\
\hline Primary turns (turns) & 4 & Secondary turns (turns) & 110 \\
\hline Maximum primary current (A) & 36 & Maximum secondary current (A) & 1.3 \\
\hline Primary wire diameter (mm) & 3 & Secondary wire diameter (mm) & 0.58 \\
\hline
\end{tabular}

- The oscillating circuit block: we use the PIC16F716 which generates two antiphase AC signals at frequency $50 \mathrm{~Hz}$. Two antiphase signals will be connected to two H-bridges hafts for voltage multiplexing at the DC-AC converter. 


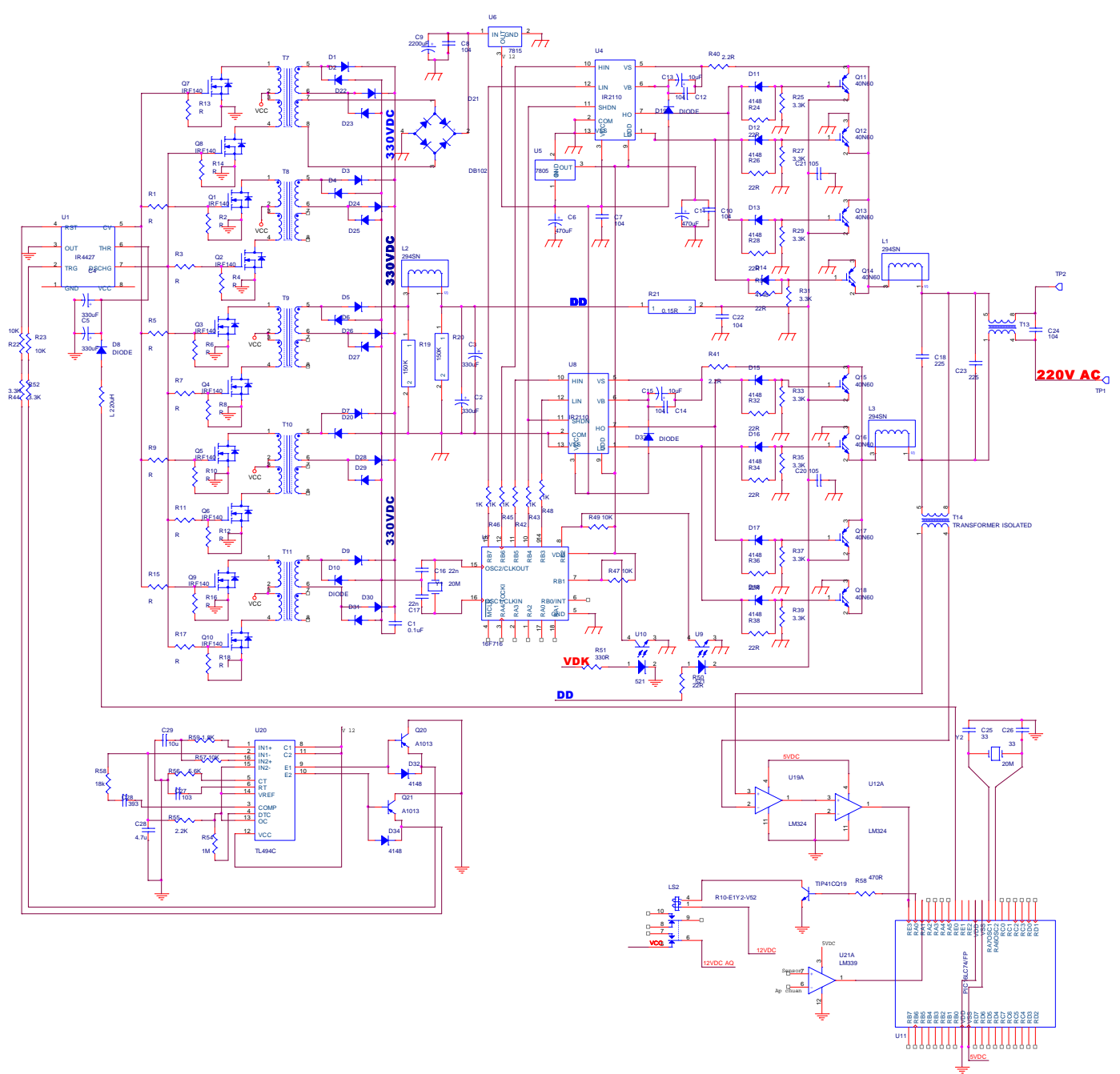

Figure 5. Schematic illustration of DC-AC inverter and protection system.

- The DC-AC converter and protection circuit block:

The DC-AC converter circuit block is designed using the IGBT 40N60A, the first H-bridge half (including ICs named Q11, Q12, Q13, Q14) and the second H-bridge half (including ICs named Q15, Q16, Q17, Q18). The output AC voltage obtained from full H-bridge is transmitted through a filter circuit block in order to filter all distortions of voltage.

The protection circuit is designed using the microchip PIC 16LC74/FP to control the operation of system based on conditions of the overload, overheating, high and low voltages. If one of which occurs, the protection circuit will shut-down and turn off the electrical generator in order to protect the system.

- The filter circuit block: this block uses the LC filter to process all voltage distortions. The LC filter is designed based on the output voltage of DC-AC converter and minimum reactive power of the filter. The output voltage is received at $220 \mathrm{VAC}$ frequency $50 \mathrm{~Hz}$ and is pure sine wave. The LC filter must satisfy the following condition [23]: 


$$
\omega_{c}^{2}=\frac{1}{L_{f} C_{f}},
$$

where $\omega_{c}$ is the corner frequency of filter, $L_{f}$ is the filter inductance, $C_{f}$ is the filter capacitance.

The inductance value $L_{f}$ can be determined by:

$$
L_{f}=\frac{D V_{\text {out }}}{2 f_{S} \Delta I_{0}},
$$

where $D$ is constant, $V_{\text {out }}$ is the output voltage, $f_{\mathrm{s}}$ is the switching frequency, $\Delta I_{0}$ is the output current ripple. By combining Eqs. (8) and (9), we get the filter inductance value at $4.1 \mathrm{mH}$ and the filter capacitance value at $330 \mu \mathrm{F}$.

\subsection{Operational description of device system}

Sea waves are random in nature and can be considered as a combination of an infinite number of waves with different frequencies and amplitudes. The change of sea waves in frequency and amplitude will affect to the operation of device system $[6,24]$. When sea waves act on the buoy, it will transfer the energy of sea waves to the generator part fixed on the bottom of the sea by rope in the vertical direction (see Fig. 1). Both of piston-rack and the gearbox are used to convert the received vertical slow motion of buoy to the high speed rotating motion with the ratio 1:30. The obtained output voltage of the generating motor is not stable because the characteristics of voltage and current depend on the rotation speed of the motor (see Fig. 4c). In our device system, the $12 \mathrm{VDC}$ voltage stabilizer is an important part to stabilize and control the output voltage of the generating motor at 12 VDC (see Fig. 4b) [8, 11]. The DC-AC inverter is used to convert the voltage $12 \mathrm{VDC}$ into the voltage $220 \mathrm{VAC}$ frequency $50 \mathrm{~Hz}$ and pure sine wave. The voltage $220 \mathrm{VAC}$ frequency $50 \mathrm{~Hz}$ is also the output voltage of the electrical generator. The performance of device is partly considered in the next section from our experimental calculation and measurement.

\section{EXPERIMENT RESULTS}

The electrical generator device for sea wave energy has operated for a long time in the Hon Dau sea, Hai Phong province, Viet Nam. At the experiment site, the sea wave amplitude is about $0.4 \div 0.5 \mathrm{~m}$. This wave amplitude range is received from the Hon Dau Hydro-Meteorological Monitoring Station. The sea wave frequency is about $1.472 \mathrm{rad} / \mathrm{s}$ (see Fig. 6), it is obtained from DASIM measurement equipment with Futek pressure sensor of America mounted on the buoy hull.

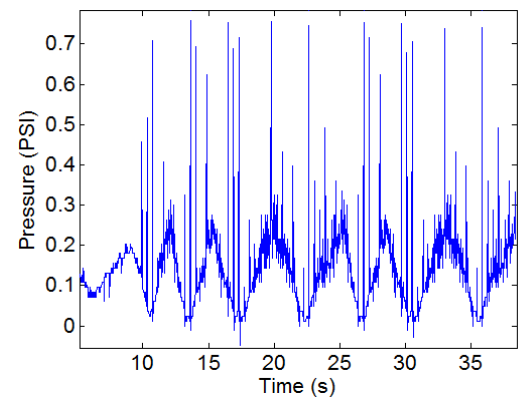

a. The sea wave pressure versus time

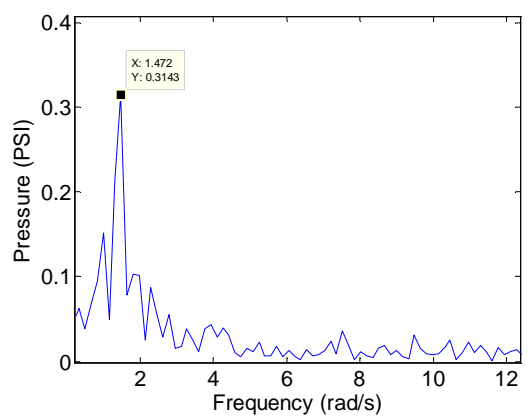

b. Pressure spectrum of sea wave

Figure 6. The sea wave pressure exerting on the buoy. 
In Fig. 6, the received average pressure value is about 0.31 psi (i.e. $0.021 \mathrm{~atm}$ in SI unit) and maximum value is 0.74 psi (i.e. $0.05 \mathrm{~atm}$ ). The obtained pressure value information will be used for the purpose of fabrication of buoy and device casing.

The output voltage received is efficient with power up to $300 \mathrm{~W}$. In this experiment, we use equipments to measure and analyze voltage and current as Picoscope USB oscilloscope 2204A of England, Gwinstek digital clamp meter of Taiwan, Kyoritsu digital clamp meter of Japan, voltage meter Sanwa CD800a of Japan, voltage meter Klein tools MM2000 of America. The measurement results received from the electrical generator during experiment at Hon Dau sea are given in Table 3. The DC-AC inverter - protection system circuit board is shown in Fig. 7.

Table 3. Measurement results received from input and output of DC-AC inverter.

\begin{tabular}{|c|c|c|c|c|c|}
\hline $\begin{array}{c}\text { Load power } \\
\mathrm{P}(\mathrm{W})\end{array}$ & $\begin{array}{c}\text { Voltage } \\
\mathrm{U}_{\mathrm{DC}}(\mathrm{VDC})\end{array}$ & $\begin{array}{c}\text { Current } \\
\mathrm{I}_{\mathrm{DC}}(\mathrm{A})\end{array}$ & $\begin{array}{c}\text { Voltage } \\
\mathrm{U}_{\mathrm{AC}}(\mathrm{VAC})\end{array}$ & $\begin{array}{c}\text { Current } \\
\mathrm{I}_{\mathrm{AC}}(\mathrm{A})\end{array}$ & $\begin{array}{c}\text { Performance } \\
\eta_{D C-A C}(\%)\end{array}$ \\
\hline 100 & 12 & 9.92 & 224 & 0.45 & 84.67 \\
\hline 140 & 12 & 13.47 & 223 & 0.61 & 84.15 \\
\hline 200 & 12 & 20.33 & 223 & 0.92 & 84.09 \\
\hline 300 & 12 & 29.5 & 221 & 1.35 & 84.27 \\
\hline
\end{tabular}

In Table 3, we use normal loads with a $40 \mathrm{~W}$ incandescent lamp and three $100 \mathrm{~W}$ incandescent lamps. The quantities $U_{D C}$ and $I_{D C}$ are voltage and current received at the output of the $12 \mathrm{VDC}$ voltage stabilizer. $U_{A C}$ and $I_{A C}$ are voltage, current received at the output of the DC$\mathrm{AC}$ inverter and protection system. The performance $\eta_{D C-A C}$ is determined from the voltage and current at the input and output of the DC-AC inverter through the experimental measurement.

The measured values in Table 3 show that the load power of the electrical generator works from $100 \mathrm{~W}$ to $300 \mathrm{~W}$, and operates stably at $200 \mathrm{~W}$ during the experiment. Fig. 8 shows the voltage and current characteristic curves versus output loads at the experiment site.

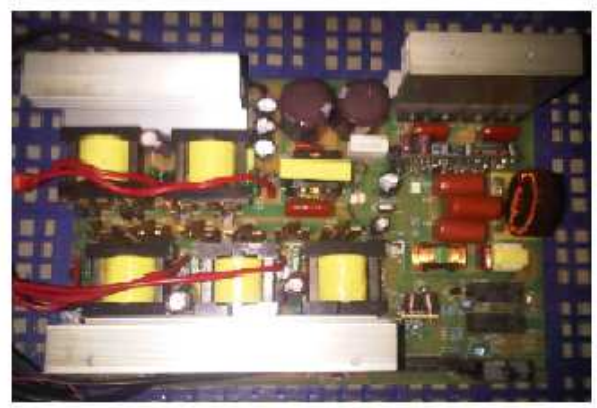

Figure 7. The DC-AC inverter and protection system circuit board.

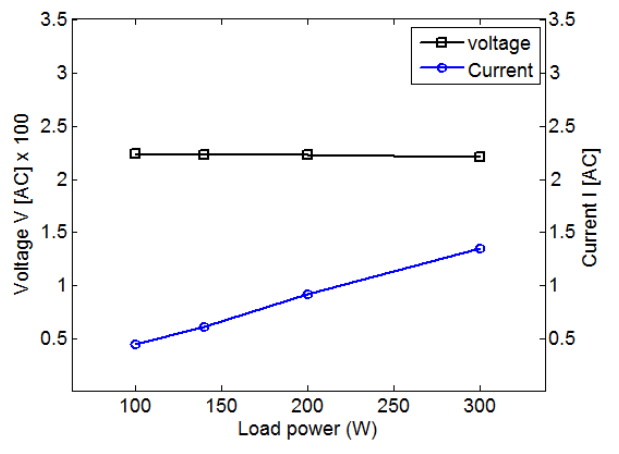

Figure 8 . The voltage and current characteristic curves versus output loads.

In Fig.1, the piston-rack of device receives the sea wave energy from the buoy through a rope. This energy is transmitted to the generating motor through the pinion and gearbox system. In practice, the input sea wave signals are random, the voltage and current at the output of the generating motor are not stable. The 12 VDC voltage stabilizer of device is used in order to stabilize the received electrical power from the generating motor output at $12 \mathrm{VDC}$ voltage. The DC-AC inverter converts the received 12 VDC voltage at the 12 VDC voltage stabilizer output to the $220 \mathrm{VAC}$ voltage and $50 \mathrm{~Hz}$ frequency (it is also the output voltage of the electrical 
generator). In Table 3, the received average performance of the DC-AC inverter is determined as follows

$$
\eta_{D C-A C}=\frac{84.67+84.15+84.09+84.27}{4}=84.295 \% .
$$

In the general case, the performance of the electrical generator is determined by the relation between the real input sea wave signals and the output power signals of the electrical generator. This relation needs to carry out many experiments for statistical calculations.

In our experiment, we use the Picoscope USB oscilloscope 2204 A and the software of signal processing to analyze the output voltage obtained from the electrical generator. In Fig. 9, it is observed that the output voltage wave on the $200 \mathrm{~W}$ load in time and in frequency is received at $220 \mathrm{VAC} \pm 1.25 \%$ frequency $50 \mathrm{~Hz} \pm 0.06 \%$ and is a pure sine wave.

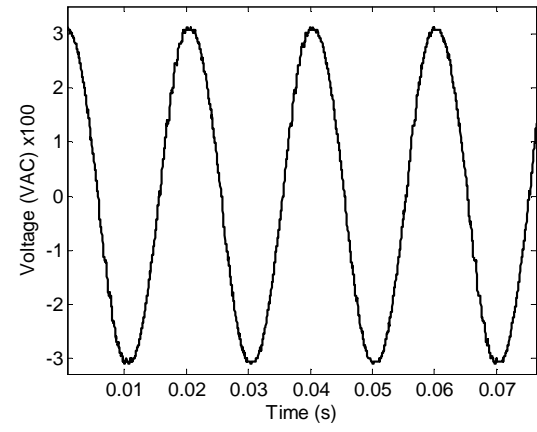

a. Output load voltage versus time

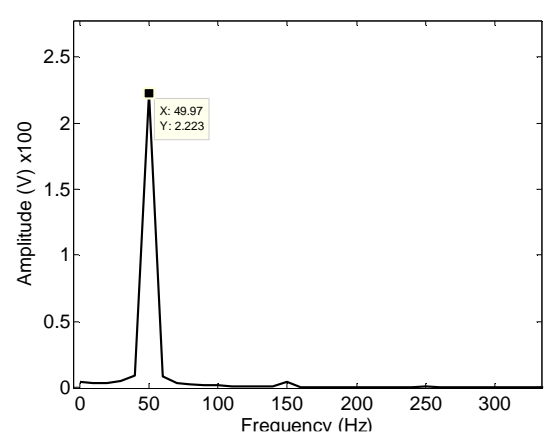

b. Spectrum of output load voltage

Figure 9. Output voltage wave on the $200 \mathrm{~W}$ load of the electrical generator for sea wave energy.

Figures 10 and 11 demonstrate several pictures of field experiments of the electrical generator for sea wave energy in the Hon Dau sea, Hai Phong province, Viet Nam.

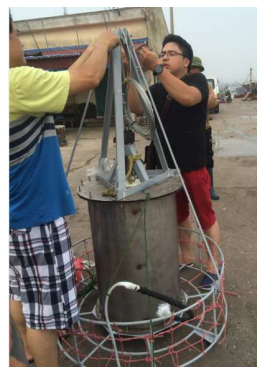

a. Preparing for experiment setup at the Hon Dau Port

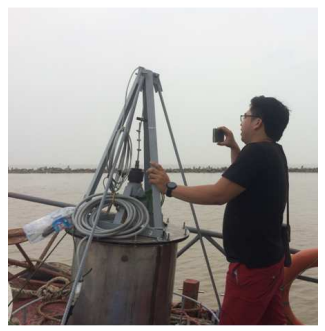

c. Moving the device to experiment site

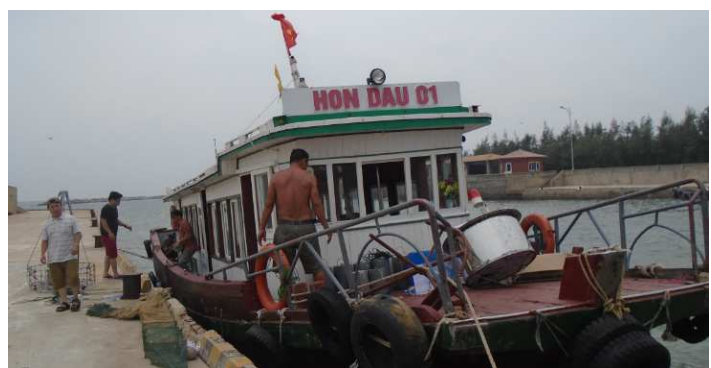

b. Uploading experiment device components onto the HQ1788 Ship

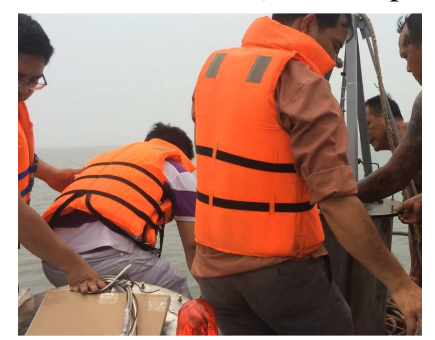

d. Experimental preparation

Figure 10. The transport of device on the HQ1788 Ship for experiment process. 

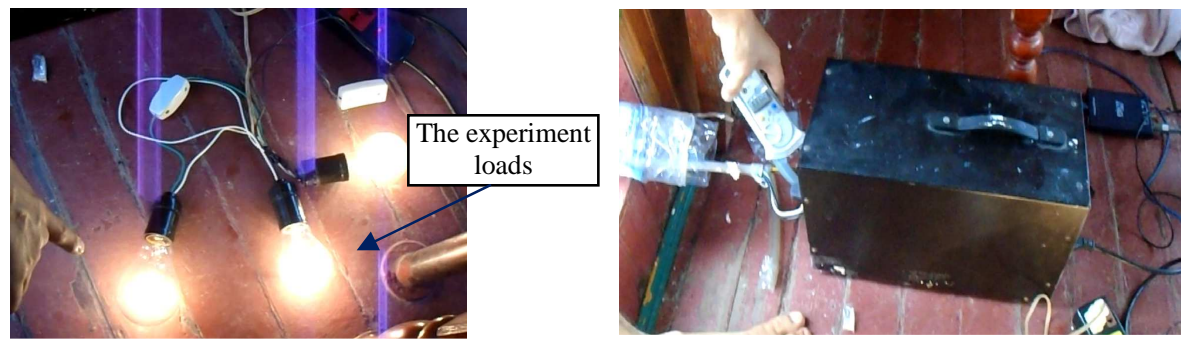

a. Testing power of device

b. Measurement of output current and voltage

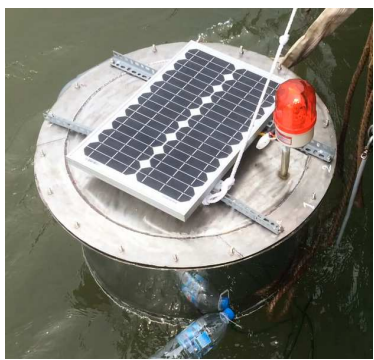

c. Buoy of device

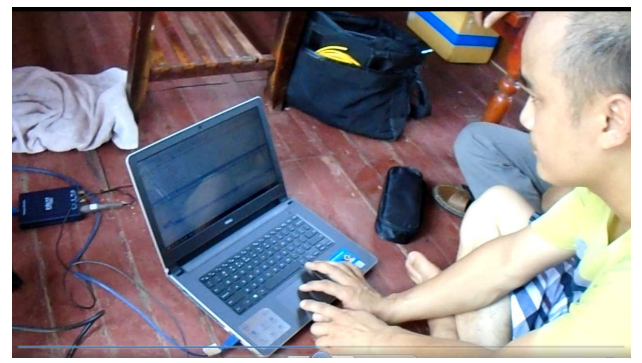

d. Analysis of output voltage and power

Figure 11. Measurement, storing and analysis of voltage and power from the electrical generator by the Picoscope USB oscilloscope 2204A connecting computer on the HQ1788 Ship.

\section{CONCLUSIONS}

In present paper, we show some results in fabrication and experiment of the electrical generator for sea wave energy. The device works in the vertical direction of sea waves, its generator part is fixed on the bottom of the sea in order to overcome the impact of sea storms as it operates at the sea. The output power of the device is generated up to $300 \mathrm{~W}$ and operates stably at $200 \mathrm{~W}$ during experiment at the sea. In the framework of experimental study of our fabricated device, the received average performance of the DC-AC inverter from 12 VDC voltage to $220 \mathrm{VAC}$ voltage is about $84.295 \%$. The output voltage is received at $220 \mathrm{VAC}$ frequency $50 \mathrm{~Hz}$ and is pure sine wave. In the general case, the performance value of the electrical generator will be investigated in the next works with the real input sea wave signals.

From our experiment results, we realize that the fabrication model is reasonable and efficient. For the obtained electrical power of device, the electrical generator for sea wave energy can be used for the signal buoy of the seaway and can supply the electrical power for the lighthouse. Moreover, at the top of buoy of device has a signal lamp and a $30 \mathrm{~W}$ solar panel. The solar panel is also extra energy source to assure that the signal lamp always operates for the time at which the sea is calm. The experiment results have also been used for analyzing the model structure in order to improve the device, and for enhancing power of the electrical generator to meet the needs of the electrical energy at island sea regions.

Acknowledgement. The authors express deep thanks to the reviewers for their helpful comments and suggestions. This research was supported by Vietnam Academy of Science and Technology (VAST), project VAST01.10/16-17. 


\section{REFERENCES}

1. Falcão A. F. O. - Modelling of Wave Energy Conversion, Instituto Superior Técnico, Universidade Técnica de Lisboa, Portugal, 2014.

2. Eriksson M., Isberg J., and Leijon M. - Hydrodynamic modelling of a direct drive wave energy converter, International Journal of Engineering Science 43 (2005) 1377-1387.

3. Stelzer M. A., and Joshi R. P. - Evaluation of wave energy generation from buoy heave response based on linear generator concepts, AIP Journal of Renewable and Sustainable Energy 4 (2012) 063137.

4. Drew B., Plummer A. R., and Sahinkaya M. N. - A review of wave energy converter technology, Proc. IMechE, Part A: Journal of Power and Energy 223 (2009) 887-902.

5. Eriksson M. - Modelling and Experimental Verification of Direct Drive Wave Energy Conversion, Uppsala University, Sweden, 2007.

6. Cargo C. J., Hillis A. J., and Plummer A. R. - Optimization and control of a hydraulic power take-off unit for a wave energy converter in irregular waves. Proceeding of the Institution of Mechanical Engineers, Part A: Journal of Power and Energy 228 (2014) 462-479.

7. Trapanese M. - Optimization of sea wave energy harvesting electromagnetic device, IEEE Transactions on Magnetics 44 (2008) 4365-4368.

8. Franzitta V., Mesineo A., and Trapanese M. - An approach to the conversion of the power generated by an offshore wind power farm connected into sea wave power generator, The Open Renewable Energy Journal 4 (2011) 19-22.

9. Engstrom J., Erikson M., Isberg J., and Leijon M. - Wave energy converter with enhanced amplitude response at frequencies coinciding with Swedish west coast sea states by use of a supplementary submerged body, Journal of Applied Physics 106 (2009) 064512.

10. Ekstrom R., Ekergard B., and Leijon M. - Electrical damping of linear generators for wave energy converters - a review. Renewable and Sustainable Energy Review 42 (2005) 116-128.

11. Choi J. H., Park J. S., Ham G. S., and Choi J. S. - Simulation of wave generation system with linear generator, Proceedings of the 3rd International Conference on Industrial Application Engineering 2015, Japan, 2015, pp. 537-541.

12. Finnegan W., Meere M., and Goggins J. - The wave excitation forces on a floating vertical cylinder in water of infinite depth. World Renewable Energy Congress Sweden 2011, pp. 2175-2182.

13. Chen Z., Yu H., Hu M., Meng G., and Wen C. - A review of offshore wave energy extraction system. Advances in Mechanical Engineering (Hindawi Publishing Corporation) (2013) 623020.

14. Guney M. S. - Wave energy conversion systems, Journal of Naval Science and Engineering 11 (2015) 25-51.

15. Mich N. T., and Cuong N. C. - Research and calculation of a generator system for wave energy with small power. National Conference on Engineering Mechanics, Ha Noi, 2014, pp. 361-366. 
16. Ba D. T., Anh N. D., and Ngoc P. V. - Numerical simulation and experimental analysis for a linear trigonal double-face permanent magnet generator used in direct driven wave energy conversion, Procedia Chemistry 14 (2015) 130-137.

17. Ba D. T. - Numerical simulation of a wave energy converter using linear generator, Vietnam Journal of Mechanics, VAST 35 (2013) 103-111.

18. Hai N. V. - Study, calculation and simulation of the linear electrical generator from sea wave energy, The Third International Scientific Conference Sustainable Energy Development, Ha Noi, 2013, pp. 172-176.

19. ITTC-Recommended Procedures: Fresh Water and Seawater Properties, $26^{\text {th }}$ ITTC Specialist Committee on Uncertainly Analysis, 2011. No. 7.5-02-01-03.

20. WindBlue Power LLC., https://www.windbluepower.com, 23 April 2016.

21. Hai N. V. - Study, design and fabrication of the smart DC-AC inverter to satisfy the charging equipment from renewable energy sources, The 2012 International Conference on Advanced Technologies for Communications, ATC/REV 2012, Ha Noi, 2012, pp. 125-129.

22. Hai N. V. - Study, design and fabrication of the electrical power system from the renewable energy sources, International Science Conference on Green Energy and Development, Ha Noi, 2012, pp. 134-141.

23. Storey N. - Electronics: A Systems Approach. Pearson Prentice Hall (Fourth Edition), 2009.

24. Hamilton L. J. - Characteristing spectral sea wave conditions with statistical clustering of actual spectra, Applied Ocean Research 32 (2010) 332-342. 